Hernández-Ramos, P., Bachen, C. M., Raphael, C., Ifcher, J., Broghammer, M. (2019). Experiencing poverty in an online simulation: Effects on players' beliefs, attitudes and behaviors about poverty. Cyberpsychology: Journal of Psychosocial Research on Cyberspace, 13(3), article 1. http://dx.doi.org/10.5817/CP2019-3-1

\title{
Experiencing Poverty in an Online Simulation: Effects on Players" Beliefs, Attitudes and Behaviors about Poverty
}

\author{
Pedro Hernández-Ramos ${ }^{1}$, Christine M. Bachen ${ }^{1}$, Chad Raphael ${ }^{1}$, John Ifcher ${ }^{1}$, \& Michael Broghammer ${ }^{2}$ \\ ${ }^{1}$ Santa Clara University, Santa Clara, CA, United States \\ 2 Pennsylvania State University, University Park, PA, United States
}

\begin{abstract}
Digital simulations are increasingly used to educate about the causes and effects of poverty, and inspire action to alleviate it. Drawing on research about attributions of poverty, subjective well-being, and relative income, this experimental study assesses the effects of an online poverty simulation (entitled Spent) on participants' beliefs, attitudes, and actions. Results show that, compared with a control group, Spent players donated marginally more money to a charity serving the poor and expressed higher support for policies benefitting the poor, but were less likely to take immediate political action by signing an online petition to support a higher minimum wage. Spent players also expressed greater subjective well-being than the control group, but this was not associated with increased policy support or donations. Spent players who experienced greater presence (perceived realism of the simulation) had higher levels of empathy, which contributed to attributing poverty to structural causes and support for anti-poverty policies. We draw conclusions for theory about the psychological experience of playing online poverty simulations, and for how they could be designed to stimulate charity and support for anti-poverty policies.
\end{abstract}

Keywords: Poverty; simulations; empathy; presence; subjective well-being

\section{Introduction}

Poverty remains a persistent and widespread problem in the United States, where an estimated 39.7 million Americans lived in poverty in 2017 (Fotenot, Semega, \& Kollar, 2018). Simply providing individuals with information about poverty does not necessarily improve their attitudes and assumptions about people who live in poverty (Steck, Engler, Ligon, Druen, \& Cosgrove, 2011). Therefore, anti-poverty organizations and educators are increasingly using simulations to introduce Americans to the causes and consequences of poverty, and improve public attitudes toward the poor. In these simulations, participants assume the role of a person struggling to find and keep a job, obtain health care and social services, and feed and clothe their families. Educators use these simulations to train health care and social service providers to meet the needs of people in poverty more effectively (Reid \& Evanson, 2016; Vandsburger, Duncan-Daston, Akerson, \& Dillon, 2010), charities have deployed simulations to inspire donations (Sandoval, 2016), and cities and advocacy organizations hold simulations to promote political support for anti-poverty policies (Bummara, 2008).

While most prior research focuses on evaluating the effects of face-to-face poverty simulations, recentlydeveloped digital poverty simulations have received less scholarly attention, despite several potential advantages (Stewart et al., 2013). Digital simulations can be easier to administer than their in-person counterparts, which depend on convening large groups to play people in poverty, as well as employers, landlords, social service 
agencies, and others. Compared with traditional media, such as print or film, digital simulations are more interactive and immersive, allowing players to enact the role of a person in poverty, not simply witness it, by making choices and experiencing the consequences for one's onscreen character (Sezen, 2013). Thus, digital simulations may promote the kind of empathy with people from other socio-economic backgrounds that face-toface poverty simulations aspire to create, while reaching larger numbers of participants (Belman \& Flanagan, 2010). In addition, because poverty simulations can allow players to interact with models of complex social systems, they may help players to understand the structural causes of poverty, which is an educational goal of most simulation designers (Sezen, 2013; Stewart et al., 2013). More broadly, there is growing evidence that digital simulations and games can improve learners' motivation and engagement, self-efficacy, knowledge acquisition, conceptual application, content understanding, and action-directed learning (Vlachopoulos \& Makri, 2017). However, skeptics suggest that digital simulations may fail to meet their learning goals because they are brief experiences, require careful post-play discussion to clarify learning goals for participants, and may impart an illusory sense of personal control over poverty as players seem to control their own fate by their choices (Roussos \& Dovidio, 2016).

The current study uses an experimental design comparing the effects of playing a digital poverty simulation with a control game to extend previous research in several ways. First, because there is far more research on the outcomes of face-to-face poverty simulations than digital simulations, we attempt to replicate prior findings that face-to-face simulations influence participants' beliefs about the causes of poverty and empathy for the poor. Second, the study examines the impact of a wider range of psychological variables on outcomes than previous studies of face-to-face and digital poverty simulations - not only empathy, but also subjective well-being and presence (an immersive sense of realism). Third, we examine a more comprehensive set of outcomes than prior studies have, including effects on participants' attitudes and beliefs about the poor, support for anti-poverty policies, and taking actions that support low-income people (donating money to charity and signing a petition to raise the minimum wage).

In addition, a mediation analysis (Hayes, 2018) enables further exploration the interrelationships and causal links among the key variables in our study. Prior research (Roussos \& Dovidio, 2016) has shown that empathic concern and beliefs about poverty function as mediating factors in influencing policies that support people living in poverty. Similarly, in this study, the role of empathy and attributions (structural or individual) of poverty are tested as possible mechanisms that explain why people may support certain welfare policies (like a higher minimum wage) and donate to organizations that help people living in poverty.

Finally, a qualitative analysis of three open-ended questions allows for further explanation about how the poverty simulation influenced beliefs and actions. The results contribute to theory about the psychological experience of online poverty simulations, whether (and why) simulations succeed to achieve their goals, and how simulations might be designed most effectively to stimulate charity and support for anti-poverty policies.

\section{Attribution Theory and Face-to-Face Poverty Simulations}

Attribution theory informs much of the research on poverty simulations. Building on Heider (1958), Feagin (1972) distinguished different ways in which people assign the causes of poverty, including making attributions internal to the individual (such as a lack of responsibility, effort, or talent) versus external or structural attributions (such as discrimination, lack of well-paying jobs, or poor schooling). Feagin theorized that these causal beliefs influence attitudes and behaviors toward people in poverty. Experimental and survey research in developed countries confirmed that those who believe in individualistic causes are more likely to blame the people who live in poverty for their condition, and are less charitable and supportive of anti-poverty policies, but in contrast, those who believe in structural causes are more willing to help the poor (e.g., Cozzarelli, Wilkinson, \& Tagler, 2001; Kluegel \& Smith, 1986; Weiner, Osborne, \& Rudolph, 2011; for a summary, see González \& Lay, 2017). While attribution theorists initially suggested that some people also attribute poverty to luck or fate, many scholars have abandoned this category, arguing that it is not conceptually and empirically distinct (Tagler \& Cozzarelli, 2013).

Simulations typically emphasize structural causes of poverty (Reid \& Evanson, 2016) and are mostly successful in imparting these beliefs. Several different face-to-face simulations have been found to build participants' understanding of structural causes, including the "deprivation trap" that can ensnare African villagers (Davidson, 
Preez, Gibb, \& Nel, 2009), the trials of Indian families engaged in low-paid piece work (Menzel, Wilson, \& Doolen, 2014), the challenges faced by formerly incarcerated women reintegrating into American society (Todman, Brodyn, Berger, Willard, \& Taylor, 2013), and the enduring effects of social stratification (Norris, 2013).

In addition, most face-to-face simulations have been found to increase participants' endorsement of the belief that poverty is structurally caused in the short-term, including C'est La Vie: The Game of Social Life (Bramesfeld \& Good, 2016), Beat the Bourgeoisie (Norris, 2013), and the Community Action Poverty Simulation (CAPS) (Nickols \& Nielsen, 2011; Noone, Sideras, Gubrud-Howe, Voss, \& Mathews, 2012; Strasser, Smith, Pendrick Denney, Jackson, \& Buckmaster, 2013; Todd, de Guzman, \& Zhang, 2011). While Zosky and Thompson (2012) found that the CAPS simulation did not increase participants' endorsement of the belief that poverty is structurally caused, participants entered this study with high structural attributions and low individual ones, which may have exerted a ceiling effect. Questions remain about the long-term effects of face-to-face simulations. For example, while Browne and Roll (2016) found that CAPS promoted short-term changes in attitudes toward poverty, awareness of why people are poor, and interest in civic action, those outcomes did not persist.

Few studies examine the effects of face-to-face poverty simulations on participants' actions. Nursing students who participated in CAPS reported subsequent changes to their clinical practice, such as advocating more for lowincome patients and providing them with more referrals to community agencies (Yang, Woomer, Agbemenu, \& Williams, 2014). Several studies measure participants' intent to act, and the findings are inconsistent. Some studies find simulations boost participants' intent to volunteer to serve the poor (Patterson \& Hulton, 2012; Yang et al., 2014), while others do not (Browne \& Roll, 2016; Davidson et al., 2009). Further, one study finds that participants did not act on their stated intentions (Neys, Van Looy, De Grove, \& Jansz, 2012).

\section{Attributions and Digital Poverty Simulations}

A smaller body of research examines digital poverty simulations. De Grove, Van Looy, Neys, and Jansz (2012) found that players of Poverty Is Not a Game (GriN Multimedia, 2010) reported modest levels of learning about poverty from the simulation, which correlated with higher levels of positive affect toward learning and greater identification with one's on-screen character. Ruggiero (2014) found that Spent (used in this study) increased students' affective learning (e.g., attitudes toward content and positive beliefs in accomplishing a learning task) about homelessness more than reading about the issue, leading to greater motivation and engagement in learning. Richey Smith, Ryder, Bilodeau, and Schultz (2016) found that playing Spent improved students' attitudes toward people in poverty, especially among participants who held the lowest opinions of the poor ex ante.

Most pertinent to our research, Roussos and Dovidio (2016) conducted two studies of players' attitudes and beliefs about poverty after playing Spent. The first study compared three groups: a treatment group that observed a video of someone else playing Spent, a treatment group that played Spent, and a control group that played a game about natural disasters (unrelated to poverty). Compared with the control group, those in the observation treatment expressed more positive feelings for the poor, lower individualistic attributions, and higher support for antipoverty programs. However, those who played Spent did not exceed the control group's scores on any of the outcome variables. Weaker beliefs in the personal controllability of poverty (which correspond with individualistic attributions), measured after play, contributed to the indirect effect of the observation condition on policy support. Thus, observing a person playing the poverty simulation was more effective than playing it at generating support for anti-poverty policy. The authors speculated that the ability to make decisions within the simulation may have led players to see poverty as controllable, and therefore to blame the poor for their condition and resist government aid. In a second study, the authors compared the impact of playing Spent on players with high and low levels of belief in meritocracy. Surprisingly, low-meritocracy participants expressed more negative attitudes toward the poor and greater belief in personal controllability of poverty after playing Spent than did lowmeritocracy participants who played a control game. The results of these two studies are in conflict with findings from most studies of face-to-face simulations, and from the Richey Smith et al. (2016) study of Spent. Roussos and Dovidio's speculation that the experience of making choices in a simulation heightens players' belief in personal responsibility for poverty is provocative but not supported by direct evidence.

Further research is needed to determine whether the impact of face-to-face and digital simulations dealing with poverty is indeed different. 


\section{Empathy and Presence}

Empathic concern is a tendency "to experience feelings of warmth, compassion and concern for others undergoing negative experiences" (Davis, 1980, p.6). Such concern is associated with responses aimed at helping others and alleviating their misfortune; it is distinguished from distress, a reaction to others' suffering that leads to avoiding victims (Batson, Fultz, \& Schoenrade, 1987). Of particular interest for this study is social empathy, the "ability to understand people by perceiving or experiencing their life situations and as a result gain insight into structural inequalities and disparities" (Segal, 2011, pp. 266-7). With both affective and cognitive components, social empathy can stimulate a commitment to work for social and economic justice and improve others' well-being (Segal, Wagaman, \& Gerdes, 2012).

Attribution research finds that viewing poverty as rooted in structural causes is associated with more empathic concern for the poor (e.g., Dovidio, Piliavin, Schroeder, \& Penner, 2006; Skitka \& Tetlock 1992), and that feeling empathy can enhance willingness to help people living in poverty (Zucker \& Weiner, 1993). Moreover, empathy is also a powerful motive for charity to relieve poverty (Slovic 2010; Willer, Wimer, \& Owens, 2015). Both face-to-face and digital poverty simulations corroborate this.

First, studies of face-to-face poverty simulations consistently find that they elicit empathy for people in poverty. The strongest findings come from research on the most widely-studied poverty simulation in the U.S., the Community Action Poverty Simulation (CAPS) (Missouri Community Action Network, 2012), which has been tested on undergraduate students of nursing, social work, public health, psychology, and sociology. These studies find that CAPS builds participants' empathy for low-income people and strengthens understanding of the experience of poverty, such as its contribution to poor health (Nickols \& Nielsen, 2011; Noone et al., 2012; Steck et al., 2011; Strasser et al., 2013; Todd et al., 2011; Vandsburger et al., 2010; Yang et al., 2014; Zosky \& Thompson, 2012). Many of these studies also demonstrate a reduction in negative attitudes toward the poor (Davidson et al., 2009; Menzel et al., 2014; Nickols \& Nielsen, 2011; Noone et al., 2012; Patterson \& Hulton, 2012; Strasser et al., 2013; Todd et al., 2011).

Second, digital poverty simulations also appear to generate empathic concern for the poor. Richey Smith et al. (2016) found that playing Spent increased empathy among undergraduates. Roussos and Dovidio's (2016) studies found that those who played Spent expressed more empathy for the poor than a control group did. Smith, Ryder, Blais, and Schnek (2017) also found that Spent boosted pharmacy students' empathy for people in poverty, and that was sustained even nine months after playing. When the same students then participated in CAPS, their levels of empathy for people living in poverty increased even more.

Several studies suggest that empathy in digital simulations is associated with the experience of presence projecting oneself into the physical or social space of the medium, and perceiving oneself as experiencing events and characters directly and realistically (Lombard \& Ditton, 1997). In a study of Inside the Haiti Earthquake, which simulates the experience of aid workers and journalists in the aftermath of a natural disaster, Bachen, HernándezRamos, Raphael, and Waldron (2016) found that presence emerged as an important experience that was positively influenced by a player's background empathy (as found by Nicovich, Boller, \& Cornwell, 2005) and also enhanced empathy for characters in the simulation (as found by Greitemeyer, Osswald, \& Brauer, 2010).

\section{Subjective Well-Being (SWB)}

While attribution theory has dominated the research on poverty simulations, the growing literature on SWB and relative income suggests another possible causal route to increased willingness to act on behalf of the poor. SWB is "a subjective evaluation of whether one is happy, content, and satisfied with his or her life" (Cheung \& Lucas, 2016, p. 332). Economists and psychologists have promoted SWB as a valuable supplement to traditional indicators that guide public policy, such as Gross Domestic Product and median income (Clark, 2018; Diener, Lucas, Schimmack, \& Helliwell, 2009).

Perceived relative income, a measure of whether we see ourselves as having more or less income than others in our reference group, is an important contributor to SWB, one that appears to be as powerful as absolute income 
(Cheung \& Lucas, 2016; Layard, Mayraz, \& Nickell, 2010). If we see ourselves as having less than our comparison group, our well-being suffers; if the opposite is true, our well-being increases.

Exposure to extreme poverty through a simulation may increase participants' SWB for two reasons. First, in comparison with the poor in the simulation, the participants may feel better off, enhancing well-being (Clark \& D'Ambrosio, 2014). Second, altruistic spending on others has been found to increase SWB (Dunn, Aknin, \& Norton, 2008; Aknin et al., 2013), and exposure to simulated poverty may increase participants' desire to support the poor, generating an "impure altruism" that aligns participants' self-interest with helping the poor (Andreoni, 1989).

\section{Hypotheses and Research Questions}

To summarize, face-to-face and digital poverty simulations, including Spent, are designed to teach about structural causes of poverty, and thus, change participants' attitudes toward people in poverty and generate greater empathy. Most research finds that simulations succeed in doing both. Thus, we hypothesize that compared with a control group:

H1: Playing Spent will increase players' beliefs that poverty is attributable to structural conditions and diminish their beliefs that poverty is caused by individual factors.

Spent was created to help solicit online contributions for an anti-poverty charity and concludes with an explicit appeal for donations. Because attribution theory and research find that belief in structural causes of poverty predicts support for anti-poverty policies and charitable donations, we anticipate that compared with a control group:

H2: Playing Spent will lead to greater support for policies to benefit the poor.

H3: Playing Spent will lead more players to take actions that benefit the poor.

The literature on SWB suggests that experiencing the life of a character in dire poverty may increase better-off participants' SWB, which may prime them to support the poor. Because this relationship has not been tested or theorized fully, we ask the following research question:

RQ1: Does playing Spent increase players' SWB?

Our final question explores the little researched but potentially important roles of empathy, presence, and SWB in contributing to willingness to help the poor. In particular, we are interested in whether these three variables help account for Spent players' support for anti-poverty policies, willingness to take action to promote a policy, and donations to aid the poor.

RQ2: What effect do presence, empathy, and SWB have on poverty-related beliefs, attitudes, and actions of Spent players?

\section{Method}

\section{Participants}

Participants were undergraduate students at a mid-size Catholic university in the western U.S., who were randomly assigned to play the treatment simulation (Spent) or a control game (Free Rice). Data were collected over two time periods, in Fall 2016 and Fall 2017. Table 1 shows that there were no significant differences in the composition of participants who played Free Rice and Spent by year of data collection, gender, race/ethnicity, age (in years), or SES. 


\begin{tabular}{|c|c|c|c|c|c|}
\hline \multirow[b]{3}{*}{ Variable } & \multirow[b]{3}{*}{ Category } & \multicolumn{2}{|c|}{ Game Played } & \multirow[b]{3}{*}{ Total } & \multirow[b]{3}{*}{ Test } \\
\hline & & Spent & Free Rice & & \\
\hline & & $n$ (Row \%) & $n$ (Row \%) & & \\
\hline \multirow[t]{3}{*}{ Year of Data Collection } & 2016 & $41(48.8)$ & $43(51.2)$ & 84 & \\
\hline & 2017 & $55(50.5)$ & $54(49.5)$ & 109 & \\
\hline & Sub-Total & 96 & 97 & 193 & $\chi^{2}(1)=0.052, p=.820$ \\
\hline \multirow[t]{3}{*}{ Gender } & Male & $51(52.6)$ & $46(47.4)$ & 97 & \\
\hline & Female & $45(48.4)$ & $48(51.6)$ & 93 & \\
\hline & Sub-Total & 96 & 94 & $190^{*}$ & $\chi^{2}(1)=0.333, p=.665$ \\
\hline \multirow[t]{4}{*}{ Race/Ethnicity } & Asian & $37(48.7)$ & 39 (51.3) & 76 & \\
\hline & White/ Caucasian & $31(52.5)$ & $28(47.5)$ & 59 & \\
\hline & $\begin{array}{l}\text { Black/Hispanic/Mixed } \\
\text { Race/Other }\end{array}$ & $26(44.8)$ & $32(55.2)$ & 58 & \\
\hline & Sub-Total & 97 & 96 & 193 & $\chi^{2}(2)=0.821, p=.663$ \\
\hline Age in Years & Mean (S.D.) & $19.72(2.36)$ & $20.03(1.99)$ & & $t(191)=-.994, p=.321$ \\
\hline $\begin{array}{l}\text { Socio-Economic Status } \\
\text { (SES)-Ten-Point Scale }\end{array}$ & Mean (S.D.) & $6.89(1.67)$ & $6.71(1.70)$ & & $t(191)=-.718, p=.474$ \\
\hline
\end{tabular}

Note. Three participants identified as other than male or female.

\section{Procedure}

Participants were recruited via e-mails and in-person announcements to student clubs and with the help of faculty colleagues who made announcements in their classes. Those who were interested were given a URL where they could enroll in the study. Potential subjects were offered $\$ 10$ for participating and a link to a survey, which contained the Human Subjects consent form and pretest measures of attitudes. After completing the pretest, participants were sent to a webpage to schedule a date and time to complete the second part of the study in a computer lab.

Participants were randomly assigned to the control or treatment before arriving at the lab. Participants in both groups played simultaneously, wearing headphones. Both groups used identical computing equipment, which were pre-set to the appropriate game. After all participants were seated, they were instructed to play their game for 15 minutes. Participants who completed Spent in under 15 minutes were asked to play again, making different choices; no participant answered all Free-Rice questions within 15 minutes. Participants were then asked to take the posttest. Next, participants approached the researcher individually, who gave them an envelope containing 10 one-dollar bills and told them they could make an anonymous donation of any part of their compensation to Catholic Charities, an agency providing services to the poor in the university's surrounding community. Each participant was then directed behind a privacy screen alone to remove as much compensation as she/he wanted to keep, leaving the remainder in the envelope and depositing it in a sealed donation box before leaving. Participant IDs were inconspicuously printed inside envelopes to track donations.

\section{Treatment and Control Materials}

Spent (playspent.org) is a single-player online simulation created in 2011 for Urban Ministries of Durham, North Carolina, a social service agency that assists people in poverty. Spent puts players in the role of a single parent with $\$ 1,000$ in savings who needs to find housing, a low-wage job, transportation, and health care for their family. The simulation challenges the player to survive a month without running out of money. Spent confronts players with difficult choices each day, such as whether to miss work to take a child to the doctor and risk being fired, or to help a family member in crisis and risk running out of money. Throughout, the simulation gives players feedback on the consequences of their choices for their health and financial well-being. Spent also uses these situations to provide information that directly or indirectly points to structural factors that keep people in poverty, such as the number of Americans working low-wage jobs. The opening screen includes links to credits, and sources for the data and scenarios presented, and the closing screen includes a link to "Donate $\$ 10$ to help someone living Spent." Thus, the simulation aims to influence players' attitudes and beliefs about poverty and the poor, and to generate donations for the sponsoring organization. 
Free Rice (freerice.com) is a simple knowledge game created by the United Nations World Food Programme to "Provide education to everyone for free" and "Help end world hunger by providing rice to hungry people for free." Players are presented with multiple-choice questions. For every correct answer 10 grains of rice are "donated through the World Food Programme to help end hunger." Players can choose questions about 21 topics. Participants were asked to answer questions about World Landmarks, Human Anatomy, and Flags of the World for about five minutes each.

Spent was chosen for the treatment condition because it emphasized structural causes of poverty and asked participants to take on the role of a person in poverty, potentially generating empathy with the poor. Free Rice was chosen for the control condition because it was another computer game that primed the concept of poverty, but did not appeal to empathy by putting players in the role of a poor character or even by representing poverty. Answering questions about landmarks, anatomy, and flags ensured that control group members were not informed about structural or individual causes of poverty while playing.

The study design minimized several threats to internal validity. The control group activity was computer-based, controlling for potential differences in students' levels of confidence in using computers (Verhoeven, Heerwegh, \& De Wit, 2010) and possible novelty effects of using computers for learning, which can increase student motivation (Annetta, Minogue, Holmes, \& Cheng, 2009). There were no on-screen representations of the player's character in Spent or Free Rice, which could have explicitly associated poverty with a particular race/ethnicity, gender, or other identity. External validity was strengthened by offering participants an opportunity to donate money and sign an online petition.

\section{Measures}

Individual attributions of poverty. This scale was created using all four measures of individual attributions of poverty developed and validated by Hunt (2002) in his abbreviated version of the foundational scales for measuring attitudes toward people in poverty developed by Feagin (1975) and Kluegel and Smith (1986). While the Hunt scale measures similar concepts as the different scales of attitudes to poverty created for other poverty simulation studies (e.g., Bramesfeld \& Good, 2016; Norris, 2013; Nickols \& Nielsen, 2011; Roussos and Dovidio, 2016; Todd et al., 2011), the Hunt scale includes more items than many of the other scales and it appears to be more widely used in the poverty literature. Items in the Hunt scale measure perceptions of personal irresponsibility, and lack of thrift, effort, and ability. Responses were measured on a five-point Likert scale from "strongly disagree" to "strongly agree," with a "neutral" option at the midpoint. Respondents who are high on this scale (range: 4 to 20) tend to attribute poverty to individual choices (pretest $\alpha=.819$; posttest $\alpha=.853$ ). Scale means and standard deviations indicate that in our sample the overall level of attribution to individual causes was lower than the midpoint of the scale (pretest $M=9.98, S D=3.52$; posttest $M=9.50, S D=3.71$ ).

Structural attributions of poverty. This scale uses four different items also developed and validated by Hunt (2002) using the same five-point Likert scale as the one used for Individual Attributions of Poverty. Attributions include society's failure to provide good schools, low wages, social prejudice, and failure of private industry to provide enough good jobs. Respondents who are high on this scale (range: 4 to 20) tend to attribute poverty to structural factors largely outside the control of individuals (pretest $\alpha=.669$; posttest $\alpha=.725$ ). Scale means and standard deviations indicate an overall level of attribution to structural causes higher than the midpoint (pretest $M=14.96, S D=2.79 ;$ posttest $M=15.28, S D=2.83$ ).

Policy support. Both the pretest and posttest used the same five-point Likert scale to measure support for three policies. To elicit informed opinions, these items mentioned potential benefits and costs of each policy: "Raise the federal minimum wage from $\$ 7.25$ to $\$ 10$ per hour, which would likely raise costs of some goods and services slightly;" "require all employers to give employees up to 7 paid sick days per year, which would likely raise costs of some goods and services slightly;" and "raise the federal income tax by $3 \%$ to pay for expanding the Food Stamp program, which helps the poor buy food." Due to high inter-correlation among these items, we combined them into a single scale (range: 4 to 20; pretest $\alpha=.687$; posttest $\alpha=.713$ ). Scale means and standard deviations indicate overall support higher than the midpoint (pretest $M=10.73, S D=2.70$; posttest $M=11.26, S D=2.72$ ). 
SWB. Participants completed "Cantril's Ladder of Life Scale" from the Gallup World Poll (Bjørnskov, 2010): "On which step of the ladder do you feel you personally stand at the present time?" where zero represents "worst possible life" and ten "best possible life." The pretest and posttest mean were $6.95(S D=1.42)$ and $7.29(S D=1.43)$, respectively.

Anti-poverty action. While completing the posttest, participants were presented with the opportunity to sign a petition to raise the federal minimum wage on the National Employment Law Project website (http://www.nelp.org). To sign the petitions, subjects supplied their name, email, and address. Participants were asked whether they signed the petition. Charitable donations were measured by the amount of compensation participants left in the envelope (as described above).

Two additional posttest measures were included for Spent players to assess their psychological states during the simulation. Because Free Rice did not include any human characters, it did not make sense to ask the control group these questions.

Presence. The posttest asked all three questions from the Social Realism subscale of the Temple Presence Inventory (Lombard, Ditton, \& Weinstein, 2004): whether participants thought the events or situations portrayed in the simulation "would occur" in the real world, whether they "could occur" in the real world, and whether "events are like the real world." The three items, each measured on a 7-point "strongly disagree" to "strongly agree" Likert scale, were combined into a linear scale with values ranging from a minimum of three (strongest disagreement) to a maximum of 21 (strongest agreement) $(\alpha=.756)$. Spent players reported presence that was higher than the midpoint $(M=18.30, S D=2.93)$.

Empathy. Adapted from Wang, et al. (2003), the empathy scale included in the posttest consisted of six items (e.g., "I could relate to the frustration that some people in poverty feel about having fewer opportunities") with a sixpoint response scale from "strongly disagree" to "strongly agree" (no midpoint). Thus, the scale ranged from six to $36(\alpha=.642)$. Spent players experienced empathy higher than the midpoint while playing the simulation $(M=27.67$, $S D=4.94)$.

\section{Analysis Plan}

All dependent variables (except petition signature) were converted to z-scores. The impact of treatment was examined on dependent variables including beliefs (individual versus structural attributions of poverty), attitudes (policy support), and two actions (donation and petition signing). Gender and SES were included as controls because each was significantly related to at least one dependent variable, and prior research on U.S. samples often finds that women are more likely to empathize with and donate more to the poor (Willer et al., 2015), and low-SES people are more likely to express willingness to support people in poverty (Clark \& D'Ambrosio, 2014). SES was measured by the MacArthur Scale of Subjective Social Status (https://macses.ucsf.edu/Research/Psychosocial/usladder.php). Pretest measures were also included as a covariate. Typically, univariate analyses of variance were employed, except for petition signature where logistic regression was used due to the binary measure. Follow-up quantitative analyses focusing exclusively on Spent players were examined using regression and mediation analysis. Qualitative analyses were also conducted to explore Spent players' narrative responses to three open-ended questions about how the simulation influenced players' understanding of the causes of poverty, how to escape it, and how players might modify the Spent simulation so that people would not experience or remain in poverty.

\section{Results}

\section{Quantitative Analyses}

H1. Playing Spent will increase players' beliefs that poverty is attributable to structural conditions and diminish their beliefs that poverty is caused by individual factors. 
This hypothesis was examined using two dependent measures: individual and structural attributions of poverty. Contrary to the hypothesis, there was no posttest difference by treatment (Individual Attributions $p=.756$; Structural Attributions $p=.223$ ), nor were gender and SES significant.

H2. Playing Spent will lead to greater support for policies to benefit the poor.

As predicted, Spent players ( $E M M=.125 \pm .072$ ) expressed significantly greater support on the posttest scale of anti-poverty policies than did Free Rice players $(E M M=-.133 \pm .072), F(1,183)=6.541, p=.011, \eta^{2}=.035$. Pretest policy support was also a significant predictor of posttest policy support, $F(1,183)=194.890, p<.001, \eta^{2}=.516$ (adjusted $R^{2}=.527$ ). Neither gender nor SES were significant.

H3. Playing Spent will lead more players to take actions that benefit the poor.

Two measures were used to test this hypothesis: signing a petition to raise the minimum wage and donations to charity. A minority of participants (61 of 191, $31.9 \%$ ) signed the petition, and contrary to $\mathrm{H} 3$, significantly more Free Rice than Spent players signed $(40.6 \%$ versus $23.2 \%), \chi^{2}(1)=6.702, p=.010$. In contrast, donations were marginally greater for Spent than Free Rice players, $F(1,162)=3.696, p=.056, \eta^{2}=.022$. Spent players $E M M=.147$ \pm .110 , Free Rice players $E M M=-.149 \pm .108$. Neither gender nor SES were significant for either action.

RQ1: Does playing Spent increase players' SWB?

Spent players reported significantly higher SWB at posttest $(E M M=.157 \pm .082)$ than did Free Rice players $(E M M=-$ $.138 \pm .083), F(1,183)=6.265, p=.013)$. The pretest covariate $F(1,183)=31.526, p<.001, \eta^{2}=.147$, and SES $F(1$, 183 ) $=33.049, p<.001, \eta^{2}=.153$, were also significant predictors (students from higher SES reported higher wellbeing). The final adjusted $R^{2}$ was .360 .

RQ2: What effect do presence, empathy, and SWB have on poverty-related beliefs, attitudes, and behaviors of Spent players?

Correlations among presence, empathy, and SWB at posttest were examined, showing a significant positive relationship between presence and empathy $(r=.304, p=.003)$, a significant negative relationship between empathy and SWB $(r=-.320, p=.002)$, and no significant relationship between presence and SWB $(r=-.047, p=$ $.651)$.

Although, as reported earlier, treatment did not make a significant difference in individual or structural attributions of poverty, an examination of Spent players showed significant pretest/posttest differences on these two beliefs, policy support, and SWB (see Table 2): Individual attributions declined; and structural attributions, policy support, and SWB increased. (The only significant difference among Free Rice players was in SWB, $M$ pretest $=6.76, \mathrm{M}$ posttest $=7.00, t(95)=-2.129, p=.036$.)

Table 2. Pretest vs. Posttest Comparisons for Spent Players Only.

\begin{tabular}{|c|c|c|c|c|c|c|c|c|c|c|}
\hline \multirow[b]{2}{*}{ Pair Comparison Pre-Post $(n=95)$} & \multirow{2}{*}{$\begin{array}{l}\text { Mean } \\
\text { Pre }\end{array}$} & \multirow{2}{*}{$\begin{array}{l}\text { Mean } \\
\text { Post }\end{array}$} & \multirow{2}{*}{$\begin{array}{l}\text { Mean } \\
\text { Dif. }\end{array}$} & \multirow{2}{*}{$\begin{array}{l}\text { Std. } \\
\text { Dev. }\end{array}$} & \multirow{2}{*}{$\begin{array}{l}\text { Std. Error } \\
\text { Mean }\end{array}$} & \multicolumn{2}{|c|}{$\begin{array}{c}\text { 95\% Confidence Interval } \\
\text { of the Difference }\end{array}$} & \multirow[b]{2}{*}{$t$} & \multirow[b]{2}{*}{ df } & \multirow{2}{*}{$\begin{array}{l}\text { Sig. }(2- \\
\text { tailed) }\end{array}$} \\
\hline & & & & & & Lower & Upper & & & \\
\hline Individual Attributions of Poverty & 10.39 & 9.76 & 0.63 & 3.07 & .315 & 0.006 & 1.257 & 2.005 & 94 & .048 \\
\hline Structural Attributions of Poverty & 14.80 & 15.34 & -0.54 & 2.68 & .275 & -1.082 & 0.009 & -1.955 & 94 & .054 \\
\hline Policy Support & 10.43 & 11.40 & -0.97 & 1.96 & .201 & -1.368 & -0.569 & -4.817 & 94 & $<.001$ \\
\hline Subjective Well Being & 7.12 & 7.59 & -0.47 & 1.69 & .174 & -0.819 & -0.129 & -2.726 & 94 & .008 \\
\hline
\end{tabular}

Note. One participant in the Spent group had missing data in one or more of these scales and was excluded from the analyses.

Separate multivariate regression analyses were conducted on the four dependent variables (individual attributions, structural attributions, policy support, and donation) with presence, empathy, SWB, gender, SES, and the pretest measures of individual attributions, structural attributions, and policy support as predictors. (Donation did not have a pretest measure.) Posttest SWB was a significant, positive predictor only of individual attributions 
of poverty (along with the pretest measure for the dependent variable), $B=.453 \pm .213, \beta=.180, t=2.129, p=.036$. Empathy positively influenced both structural attributions of poverty $(B=.151 \pm .054, \beta=.259, t=2.795, p=.006)$ and policy support $(B=.157 \pm .039, \beta=.298, t=4.059, p<.001)$, as did the respective pretest measures of structural attributions of poverty and policy support. None of the predictors were significant with donation as the dependent variable.

Additional analyses were conducted on a more complex model that tested for presence as an antecedent variable, empathy and structural attributions of poverty as mediating variables, and policy support as a dependent variable (see Figure 1). Mediation analysis (conducted using the Process macro in SPSS by Andrew F. Hayes; Hayes, 2018) was used to test the model.

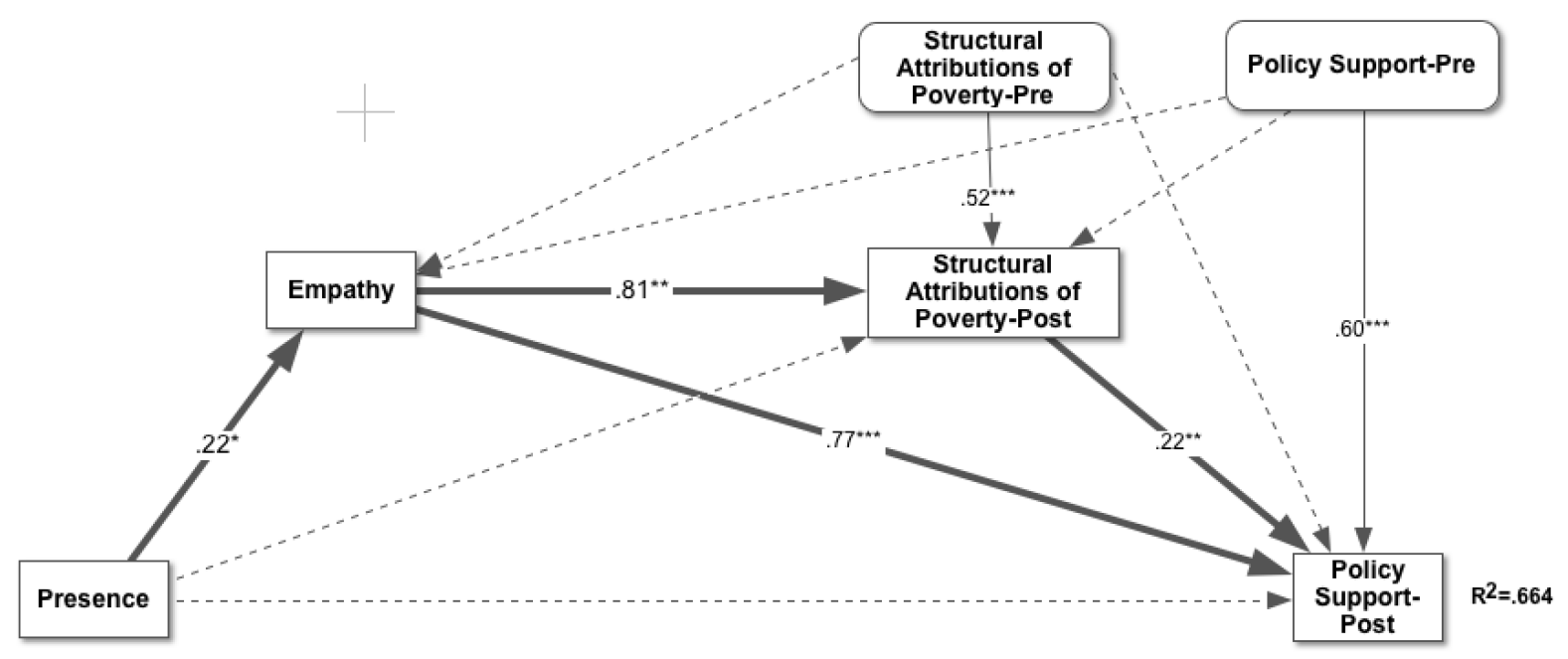

Figure 1. Mediation model diagram. Numbers are coefficients. Dashed lines indicate non-significant coefficients. Asterisks indicate $\mathrm{p}$-values: $*=p<.05 ; * \star=p<.01 ; * \star \star=p<.001$.

Results show that despite the lack of a significant direct effect of presence on policy support, presence had two indirect paths through which it influenced policy support, one through empathy alone (Effect $=.1689$, Boot $S E=$ $.0842,95 \% \mathrm{Cl}[.0346, .3601])$ and the other through empathy and structural attributions of poverty (Effect $=.0389$, Boot $S E=.0273,95 \% \mathrm{Cl}[.0019, .1063]$, final model $\left.R^{2}=.6639\right)$. These effects were robust despite the presence of the covariates, suggesting that as players experienced greater realism within Spent they developed more empathy, increased in their understanding of poverty as caused by structural factors, and consequently expressed support for policies that benefit the poor.

A second mediation model included donation amount as the dependent variable with empathy, structural attributions of poverty, and policy support as mediators. This was not successful at explaining the observed results (final model $R^{2}=.1089$ ), with none of the coefficients nor any of the indirect paths achieving significance. Thus, although Spent players donated marginally more than Free Rice players, this model does not provide additional insights on what factors influenced their donation behavior.

Summary of quantitative results. In sum, we found no significant differences between Spent and Free Rice on either individual or structural attributions of poverty (H1). H2 was supported: Spent players expressed greater support than Free Rice players on policies benefitting the poor. H3 was partially supported: Spent players donated marginally more than Free Rice players. However, contrary to expectations, a lower proportion of Spent players than Free Rice players signed an online petition.

A closer examination of Spent players only demonstrated that the game significantly increased structural attributions of poverty and decreased individual attributions of poverty, changes that did not occur for Free Rice players. We also found that Spent players reported significantly higher SWB at posttest than Free Rice players (RQ1). Regarding RQ2, multivariate analyses found that changes in SWB were positively related only to individual attributions of poverty. Empathy positively affected both structural attributions of poverty and policy support. 
Finally, a mediation model showed that empathy and structural attributions of poverty are positive and significant mediators of the impact of presence on policy support, but that the model did not predict donation amount.

\section{Qualitative Analysis}

After examining trends in the first wave of data collection (conducted in 2016), we sought to understand more about why participants took actions to address poverty or declined to do so. This prompted us to add several open-ended questions to the posttest for Spent used in the second wave of data gathering (in 2017):

(1) How, if at all, did the simulation (computer) game affect your understanding about why there is poverty?

(2) How, if at all, did the simulation (computer) game affect your understanding about how people can get out of poverty?

(3) Imagine you can recommend a modification to the options available to the player of the game so that people would not experience or remain in poverty. What modification would you recommend?

The open-ended questions were not included in the Free Rice posttest because that game did not address any causes or ways out of poverty, so these questions would not have made sense to the control group participants. We analyzed the open-ended responses by Spent players in 2017 ( $N=55$ of 96 total Spent players) to answer two additional research questions that emerged from our quantitative findings: (1) Why didn't more Spent players sign the petition? (2) Why did Spent players donate marginally more to charity than Free Rice players?

All responses to these questions by the Spent players in 2017 were coded and then combined into larger themes, defined as patterns that capture "something significant or interesting about the data and/or research question" (Maguire \& Delahunt, 2017, p. 3356). Themes in the responses were identified both deductively and inductively: given our interest in structural and individualistic understandings of poverty, SWB, and empathy, we coded for responses that mentioned these themes, yet we also remained open to any additional themes that emerged from inductive analysis of the data. To minimize the risk of imposing meaning on the responses, we coded them for their semantic (explicit or surface) meaning, but did not try to interpret their latent (underlying) meaning. A single response could have been coded as containing multiple themes, such as expressing "empathy" and mentioning "structural causes of poverty." To answer our two research questions, we compared responses from Spent players who signed the petition and those who did not sign, and then compared responses from Spent players who donated and those who did not donate. For brevity's sake, we only report themes that were mentioned most often by at least one group (signers or nonsigners, donors or nondonors).

Why didn't more Spent players sign the petition? Two potential explanations emerge from the qualitative coding. First, the simulation's focus on challenging players to make short-term, individual choices to stay afloat financially may have made structural causes of poverty salient, but not structural solutions. Spent immerses players in the individual's experience of poverty. While the simulation provides information that generalizes from the player's experience and its causes to other Americans in poverty, Spent does not mention social or policy solutions to poverty. The simulation also does not give players many choices to pursue those kinds of remedies. For example, the player is not offered choices to engage in collective or political action, except to speak up for a union in the workplace, which is punished by firing. Structural efforts, such as advocating a law to raise the minimum wage, also take longer to bear fruit than the short-term choices that Spent challenges players to make to remain solvent for one month.

There is evidence to support this interpretation in the responses to several open-ended questions posed to Spent players on the posttest. One question asked how, if it all, the simulation "affect[ed] your understanding about why there is poverty." Structural causes of poverty were mentioned in roughly equal proportions by Spent players who signed the petition for a higher minimum wage (39\%, $N=5$ of 13 total signers) and those who did not sign (41\%, $N=17$ of 42 total nonsigners). But when asked how the simulation "affect[ed] your understanding about how people can get out of poverty," only two participants, who both signed the petition, mentioned structural solutions to escaping poverty (government aid or higher minimum wages). For example, one player wrote that the simulation "gave me very little hope that it was possible [to escape poverty]. The only bright light in the game is 
the application for food stamps, which takes another month to become active - rendering them useless, since most people would apply for them only right when they run out of food."

Players were also asked to recommend a modification to the options available to Spent players that would allow people to "not experience or remain in poverty." Only one participant mentioned adding more opportunities for political action and only three mentioned more options to apply for government aid.

Second, because Spent is designed to introduce players to the difficulty of escaping poverty, it may have dampened players' belief in the effectiveness of political action. Taking political action depends in part on individuals' sense of self-efficacy (the belief that they can influence society) and collective efficacy (the belief that society is open to influence) (Colby, Beaumont, Ehrlich, \& Corngold, 2010). Spent is a poverty simulation, not a policy or government simulation. It offers only one option to join a collective action, and that choice (supporting a union in the workplace) ends badly for the player, who is fired. When asked to propose a modification to the simulation that might help lift more players out of poverty, $60 \%(N=25$ of 42$)$ of respondents who did not sign the petition failed to list a single way, while only $23 \%$ ( $N=3$ of 13 ) of those who signed could not list one.

Why did Spent players donate more to charity than Free Rice players? Learning something new about the causes of poverty may have boosted donations. When asked how, if at all, the simulation "affect[ed] your understanding about why there is poverty," $61 \%(N=11$ of 18$)$ of nondonors said Spent had no effect, while only $28 \%(N=10$ of 36$)$ of donors said this. Thus, nondonors were over twice as likely as donors to say that they did not learn anything from the simulation that added to their understanding of the causes of poverty. The ability to see ways out of poverty did not correlate with whether players donated to charity. When asked how the simulation influenced their understanding of ways to escape poverty, $50 \%(N=9$ of 18$)$ of nondonors could list at least one way to get out of poverty, while $44 \%(N=16$ of 36$)$ who donated could list at least one way to get out.

\section{Discussion}

This experiment tested whether an online role-playing poverty simulation (Spent) was more effective than a control game (the online quiz game Free Rice) in changing beliefs about poverty, generating increased support for policies that benefit the poor, and encouraging behaviors including charitable donations and signing a petition to increase the federal minimum wage. The analyses explored mechanisms by which the experience of playing Spent affected poverty-related beliefs, attitudes, and behavior.

Attribution theory partially explains our findings. Spent players showed significant changes between pretest and posttest in their attributions of poverty, increasing structural and decreasing individual attributions, in line with prior research on Spent by Richey Smith et al. (2016). This result was not found for Free Rice players. However, the direct comparison between Spent and Free Rice was not statistically significant, replicating Roussos and Dovidio's (2016) finding that playing Spent was no more effective at shifting attributions than playing a control game that did not simulate poverty.

We are less concerned than Roussos and Dovidio that an inherent property of digital simulations, the ability to make choices as one's character, influenced players to see poverty as the product of personal responsibility. Unlike Roussos and Dovidio, we found that Spent did shift players' attributions from individual to structural causes. We think there are three additional plausible explanations for why Spent did not change these attributions more dramatically: the design of this particular simulation does not foreground systemic causes as explicitly as it might; players need more than 15 minutes of play to appreciate the role of structural factors; or they need the kind of debriefing sessions that are commonly used in face-to-face poverty simulations to grasp these factors fully. Still, it is noteworthy that the simulation's influence on poverty attributions did not differ significantly by gender or SES, given that research on Americans often finds that males more than females and high-SES more than low-SES people are more likely to assign poverty to individualistic causes (González \& Lay, 2017). A less compelling learning experience might have been able to influence only those groups most predisposed to structural attributions.

This is the first experiment to show that a poverty simulation (face-to-face or digital) can increase donations to help the poor, even if marginally, indicating the potential value of simulations as a tool for promoting charity. While females tend to give more to charity and low-SES people often give a larger proportion of their income (Willer et 
al., 2015), the simulation was equally effective at inspiring absolute amounts of charitable donations across differences in gender and SES. Qualitative analyses suggest that this effect was magnified by learning new information about poverty, as those who mentioned more new insights into poverty's causes on the posttest were more likely to donate. This may mean that poverty simulations are especially effective at soliciting donations from those who know least about the sources of poverty. It may also mean that simulations should introduce novel information that is not widely known about poverty's causes, consequences, and potential solutions, not simply illustrate experiences that are more familiar to players. However, the fact that we found no relationship between donating and attributions of poverty, empathy, presence, or SWB, means that there is much more to learn about how poverty simulations motivate charitable giving.

In particular, although playing Spent increased participants' SWB, as the literature on SWB and relative income suggested was possible, this did not translate into a structural view of poverty, donating, or taking policy action. In fact, higher SWB at posttest was more likely to predict attributing poverty to individual causes and lower empathy. As this was the first study to examine SWB and poverty simulations, we think the variable deserves further research, especially as part of mediation analyses that include additional variables (mentioned below in the section on future research).

The simulation's ability to stimulate political attitudes and action to address structural causes of poverty yielded mixed results. As attribution theory and prior research on face-to-face simulations led us to believe, we found that Spent promoted higher support for anti-poverty policies than the control game did. Mediation analysis revealed that presence, empathy, and structural attributions contributed to policy support. Participating in a brief, 15minute poverty simulation appeared to foster greater social empathy, which prior research suggests can inspire commitments to social justice (Segal et al., 2012). We conclude that digital poverty simulations should be designed to promote presence and empathy, especially because our results confirm previous findings that experiencing each state promotes learning from digital simulations (e.g., Bachen et al., 2016), and that empathy contributes to a structural analysis of poverty (Dovidio et al., 2006) and inspires support for aiding the poor (Zucker \& Weiner, 1993).

However, greater willingness to assist the poor may be short-lived and may not translate into action (Browne \& Roll, 2016; Neys et al., 2012). Indeed, we found Spent players were less willing than Free Rice players to take immediate action to sign a petition to boost the minimum wage. Several explanations are possible. First, because playing Spent was likely a more emotionally engaging and potentially disturbing experience than completing the Free Rice quizzes, Spent players may have had less energy left to fill out the petition; as Clark and Mayer observe, "psychological engagement [in simulations] may or may not be accompanied by behavioral engagement" (2016, p. 223). Second, differences between the control game and simulation meant that the Spent posttest was a little longer than the Free Rice posttest (to include measures of presence and empathy, which were not germane to the control game). If Spent players experienced survey fatigue, this may have discouraged them from reading and signing the petition and/or making donations. Third, qualitative data suggest that players did not see Spent-which was designed primarily to elicit donations-as demonstrating the existence of structural solutions to poverty or inspiring a sense of efficacy about pursuing them. Incorporating these elements into simulations might spark political action more effectively.

On the whole, our results suggest that different psychological experiences in digital simulations influence causal attributions about poverty, promote charity, and inspire political action. No single variable, even empathy or presence, seems likely to motivate all of these distinct responses to experiencing poverty vicariously, and there is more to learn what motivates each of them.

\section{Limitations and Future Research}

Subsequent research can address several limitations of this study. First, our sample of students from a private, Catholic university in the western U.S. may have affected results in several ways. The sample entered the experiment with high levels of empathy and structural attributions of poverty, which may have made them more receptive to the simulation's message but may also have exerted ceiling effects on participants' ability to strengthen their existing attitudes and beliefs. Inviting participants to donate to Catholic Charities could have inspired greater giving than naming a charity that was secular or less familiar to participants. Future studies should 
seek more diverse samples, especially by age, work status, and political ideology, which are known to affect beliefs and attitudes about poverty (Clark \& D'Ambrosio, 2014), and consider the choice of charity carefully for greater generalizability.

Second, future research should compare poverty simulations to additional control experiences. We chose Free Rice because it reminded players that poverty exists but did not put players in the shoes of someone in poverty, which helped isolate the impact on the treatment group of experiencing poverty vicariously in the Spent simulation. Free Rice may have primed players to donate to the poor more than a game that did not remind them about poverty. Moreover, with every correct answer to a quiz question, the Free Rice players generated micro-donations of rice to the UN World Food Programme. When asked to consider giving to the poor at the end of the experiment, players may have felt they already had made a donation while playing, or they may have been primed to donate more than they would have otherwise. Additionally, differences between the control game and simulation meant that the Spent posttest was a little longer than the Free Rice posttest (to include measures of presence and empathy, which were not germane to the control game). This may have contributed to survey fatigue for Spent players, discouraging petition signing and/or donations. Future research should ensure that posttests are similar in length, by adding distractor items if necessary. It would also be useful to compare the effects of digital and face-to-face simulations to understand potential advantages and trade-offs of moving simulations online.

Third, we tested short-term effects of the simulation in isolation, rather than embedding it in a larger learning context. As noted above, face-to-face poverty simulations are typically social experiences that unfold over a longer period, and involve debriefing sessions to compare impressions and reinforce the structural causes of poverty. Thus, research that compares digital and face-to-face simulations should attempt to address these disparities, while also measuring longer-term attitudinal and belief changes and how they affect behavior. Researchers can build on this kind of work by including open-ended questions and interviews to shed more light on how and why simulations inspire changes or not.

Fourth, attribution theorists have recently developed more complex models of perspectives on poverty, which are based on an individual's beliefs about the locus, stability, personal control, and other control of poverty (Osborne \& Weiner, 2015). This approach suggests that each person's views of poverty are the product of several antecedent beliefs about causes, rather than just individual or structural attributions. Future research on poverty simulations could employ this version of attribution theory, which may be more predictive of outcomes.

Fifth, the literature on inequality and poverty suggests many other beliefs and attitudes that can influence assistance to people in poverty than we could include in this study, which are ripe for testing on poverty simulations. These include beliefs about the amounts of existing government and charitable assistance, efficacy of aid, and income mobility and inequality (Luccasen, Thomas, \& Grossman, 2017; Willer et al., 2015). They also include attitudes toward in-group and out-group membership, conformity and social influence, social responsibility, self-interest and fairness (Clark \& D'Ambrosio, 2014; González \& Lay, 2017). As this list of variables suggests, it is unlikely that a single poverty simulation will appeal equally effectively to everyone, but a fuller understanding of how stepping into the virtual shoes of a person in poverty affects beliefs and attitudes could convince more people to donate or take political action on behalf of the poor.

\section{Acknowledgement}

This research was supported through a University Research Grant, Santa Clara University.

\section{References}

Aknin, L. B., Barrington-Leigh, C. P., Dunn, E. W., Helliwell, J. F., Burns, J., Biswas-Diener, R., .. Norton, M. I. (2013). Prosocial spending and well-being: Cross-cultural evidence for a psychological universal. Journal of Personality and Social Psychology, 104, 635-652. https://doi.org/10.1037/a0031578

Andreoni, J. (1989). Giving with impure altruism: Applications to charity and Ricardian equivalence. Journal of Political Economy, 97, 1447-1458. https://doi.org/10.1086/261662 
Annetta, L. A., Minogue, J. M., Holmes, S. Y., \& Cheng, M.-T. (2009). Investigating the impact of video games on high school students' engagement and learning about genetics. Computers \& Education, 53, 74-85.

https://doi.org/10.1016/j.compedu.2008.12.020

Bachen, C. M., Hernández-Ramos, P., Raphael, C., \& Waldron, A. (2016). How do presence, flow, and character identification affect players' empathy and interest in learning from a serious computer game? Computers in Human Behavior, 64, 77-87. https://doi.org/10.1016/j.chb.2016.06.043

Batson, D. C., Fultz, J., \& Schoenrade, P. A. (1987). Distress and empathy: Two qualitatively distinct vicarious emotions with different emotional consequences. Journal of Personality, 55, 19-39. https://doi.org/10.1111/j.14676494.1987.tb00426.x

Belman, J., \& Flanagan, M. (2010). Designing games to foster empathy. International Journal of Cognitive Technology, 14(2)/15(1), 11-21.

Bjørnskov, C. (2010). How comparable are the Gallup World Poll life satisfaction data? Journal of Happiness Studies, 11, 41-60. https://doi.org/10.1007/s10902-008-9121-6

Bramesfeld, K. D., \& Good, A. (2016). C'est La Vie! The Game of Social Life: Using an intersectionality approach to teach about privilege and structural inequality. Teaching of Psychology, 43, 294-304.

https://doi.org/10.1177/0098628316662758

Browne, L. P., \& Roll, S. (2016). Toward a more just approach to poverty simulations. Journal of Experiential Education, 39, 254-268. https://doi.org/10.1177/1053825916643832

Bummara, C. (2008). Using poverty simulations to build support for poverty reduction initiatives: A municipal action guide. Washington, D.C.: National League of Cities.

Cheung, F., \& Lucas, R. E. (2016). Income inequality is associated with stronger social comparison effects: The effect of relative income on life satisfaction. Journal of Personality and Social Psychology, 110, 332-341.

https://doi.org/10.1037/pspp0000059

Clark, A. E. (2018). Four decades of the economics of happiness: Where next? The Review of Income and Wealth, 64, 245-269. https://doi.org/10.1111/roiw.12369

Clark, A. E., \& D'Ambrosio, C. (2014). Attitudes to income inequality: Experimental and survey evidence, IZA Discussion Paper, No. 8136. Bonn, Germany: Institute for the Study of Labor (IZA).

Clark, R. E., \& Mayer, R. (2016). E-learning and the science of instruction. Proven guidelines for consumers and designers of multimedia learning. Hoboken, NJ: John Wiley \& Sons.

Colby, A., Beaumont, E., Ehrlich, T., \& Corngold, J. (2010). Educating for democracy: Preparing undergraduates for responsible political engagement. San Francisco, CA: Jossey-Bass.

Cozzarelli, C., Wilkinson, A. V., \& Tagler, M. J. (2001). Attitudes toward the poor and attributions for poverty. Journal of Social Issues, 57, 207-227. https://doi.org/10.1111/0022-4537.00209

Davidson, J. H., Preez, L. D., Gibb, M. W., \& Nel, E. L. (2009). It's in the bag! Using simulation as a participatory learning method to understand poverty. Journal of Geography in Higher Education, 33, 149-168.

https://doi.org/10.1080/03098260802276672

Davis, M. H. (1980). A multidimensional approach to individual differences in empathy. JSAS Catalog of Selected Documents in Psychology, 10, 85. 
De Grove, F., Van Looy, J., Neys, J., \& Jansz, J. (2012). Playing in school or at home? An exploration of the effects of context on educational game experience. Electronic Journal of e-Learning, 10, 199-208.

Diener, E., Lucas, R., Schimmack, U., \& Helliwell, J. (2009). Well-being for public policy. New York, NY: Oxford University Press.

Dovidio, J. F., Piliavin, J. A., Schroeder, D. A., \& Penner, L. A. (2006). The social psychology of prosocial behavior. Mahwah, NJ: Lawrence Erlbaum.

Dunn, E. W., Aknin, L. B., \& Norton, M. I. (2008). Spending money on others promotes happiness. Science, 319(5870), 1687-1688. https://doi.org/10.1126/science.1150952

Feagin, J. (1972). Poverty: We still believe that God helps them who help themselves. Psychology Today, 6(6), 101129.

Feagin, J. (1975). Subordinating the poor. Englewood Cliffs, NJ: Prentice Hall.

Fontenot, K., Semega, J., \& Kollar, M. (2018). Income and Poverty in the United States: 2017 (Report No. P60-263)

Retrieved from the U.S. Census Bureau, Current Population Reports website:

https://www.census.gov/content/dam/Census/library/publications/2018/demo/p60-263.pdf

González, R., \& Lay, S. (2017). Sense of responsibility and empathy: Bridging the gap between attributions and helping behaviours. In E. van Leeuwen \& H. Zagefka (Eds.), Intergroup Helping (pp. 331-347). Cham, Switzerland: Springer.

Greitemeyer, T., Osswald, S., \& Brauer, M. (2010). Playing prosocial video games increases empathy and decreases schadenfreude. Emotion, 10, 796-802. https://doi.org/10.1037/a0020194

GriN Multimedia. (2010). Poverty Is Not a Game [Computer game]. Brussels: King Baudouin Foundation. Retrieved from http://www.grin.be/blog/?p=38

Hayes, A. F. (2018). Introduction to mediation, moderation, and conditional process analysis. A regression-based approach ( $2^{\text {nd }}$ ed.). New York and London: The Guilford Press.

Heider, F. (1958). The psychology of interpersonal relations. New York: Wiley.

Hunt, M. O. (2002). Religion, race/ethnicity, and beliefs about poverty. Social Science Quarterly, 83, 810-831. https://doi.org/10.1111/1540-6237.00116

Kluegel, J. R., \& Smith, E. R. (1986). Beliefs about inequality: Americans' views of what is and what ought to be. New York: Aldine De Gruyter.

Layard, R., Mayraz, G., \& Nickell, S. (2010). Does relative income matter? Are the critics right? In E. Diener, J. F. Helliwell, \& D. Kahneman (Eds.), International differences in well-being (pp. 139-165). New York: Oxford University Press.

Lombard, M., \& Ditton, T. (1997). At the heart of it all: The concept of presence. Journal of Computer Mediated Communication, 3(2). https://doi.org/10.1111/j.1083-6101.1997.tb00072.x

Lombard, M., Ditton, T., \& Weinstein, L. (2004). Measuring presence: The Temple Presence Inventory (TPI). Retrieved from http://matthewlombard.com/research/p2_ab.html

Luccasen, R. A., Thomas, M. K., \& Grossman, P. J. (2017). Giving to poverty relief charities: The impact of beliefs and misperceptions toward income redistribution in a real donation experiment. Social Choice and Welfare, 49, 387-409. https://doi.org/10.1007/s00355-017-1070-8 
Maguire, M., \& Delahunt, B. (2017). Doing a thematic analysis: A practical step-by-step guide for learning and teaching scholars. AISHE-J: The All Ireland Journal of Teaching and Learning in Higher Education, 9(3). Retrieved from http://ojs.aishe.org/aishe/index.php/aishe-j/article/view/335

Menzel, N., Wilson, L. H. \& Doolen, J. (2014). Effectiveness of a poverty simulation in Second Life ${ }^{\circ}$ : Changing nursing student attitudes toward poor people. International Journal of Nursing Education Scholarship, 11(1), 1-7. https://doi.org/10.1515/ijnes-2013-0076

Missouri Community Action Network (2012). Community action poverty simulation (CAPS). Retrieved from http://www.povertysimulation.net

Neys, J., Van Looy, J., De Grove, F., \& Jansz, J. (2012, May). Poverty is not a game: Behavioral changes and long-term effects after playing PING. Paper presented at the 62nd Annual ICA Conference, Phoenix, AR.

Nickols, S. Y., \& Nielsen, R. B. (2011). "So many people are struggling": Developing social empathy through a poverty simulation. Journal of Poverty, 15, 22-42. https://doi.org/10.1080/10875549.2011.539400

Nicovich, S. G., Boller, G. W., \& Cornwell, T. B. (2005). Experienced presence within computer-mediated communications: Initial explorations on the effects of gender with respect to empathy and immersion. Journal of Computer-Mediated Communication, 10(2). http://dx.doi.org/10.1111/j.1083-6101.2005.tb00243.x

Noone, J., Sideras, S., Gubrud-Howe, P., Voss, H., \& Mathews, L. R. (2012). Influence of a poverty simulation on nursing student attitudes toward poverty. Journal of Nursing Education, 51, 617-622.

https://doi.org/10.3928/01484834-20120914-01

Norris, D. R. (2013). Beat the Bourgeoisie: A social class inequality and mobility simulation game. Teaching Sociology, 41, 334-345. https://doi.org/10.1177/0092055X13490751

Osborne, D., \& Weiner, B. (2015). A latent profile analysis of attributions for poverty: Identifying response patterns underlying people's willingness to help the poor. Personality and Individual Differences, 85, 149-154. https://doi.org/10.1016/j.paid.2015.05.007

Patterson, N., \& Hulton, L. J. (2012). Enhancing nursing students' understanding of poverty through simulation. Public Health Nursing, 29, 143-151. https://doi.org/10.1111/j.1525-1446.2011.00999.x

Reid, C. A., \& Evanson, T. A. (2016). Using simulation to teach about poverty in nursing education: A review of available tools. Journal of Professional Nursing, 32, 130-140. https://doi.org/10.1016/j.profnurs.2015.10.002

Richey Smith, C. E., Ryder, P. Bilodeau, A., \& Schultz, M. (2016). Use of an online game to evaluate health professions students' attitudes toward people in poverty. American Journal of Pharmaceutical Education, 80(8), article 139. Retrieved from https://www.ajpe.org/doi/full/10.5688/ajpe808139

Roussos, G., \& Dovidio, J. F. (2016). Playing below the poverty line: Investigating an online game as a way to reduce prejudice toward the poor. Cyberpsychology: Journal of Psychosocial Research on Cyberspace, 10(2), article 3. https://doi.org/10.5817/CP2016-2-3

Ruggiero, D. N. (2014, April). Spent: changing students' affective learning toward homelessness through persuasive video game play. In Proceedings of the 32nd annual ACM conference on Human Factors in Computing Systems (pp. 3423-3432), Toronto, Canada: ACM.

Sandoval, T. (2016, March 4). Simulating poverty gives charity supporters a taste of hard times. Chronicle of Philanthropy. Retrieved from https://www.philanthropy.com/article/Simulating-Poverty-Gives/235578 
Segal, E. A. (2011). Social empathy: A model built on empathy, contextual understanding, and social responsibility that promotes social justice. Journal of Social Service Research, 37, 266-277.

https://doi.org/10.1080/01488376.2011.564040

Segal, E. A., Wagaman, M. A., \& Gerdes, K.E. (2012). Developing the social empathy index: An exploratory factor analysis. Advances in Social Work 13, 541-560. Retrieved from

http://journals.iupui.edu/index.php/advancesinsocialwork/article/view/2042

Sezen, T. I. (2013). The representations of poverty in digital games. In V. Bernard \& S. Oksay (Eds.), Images (II)Images of the Poor: The Conference Proceedings (pp. 47-61). Berlin: LIT Verlag.

Skitka, L. J., \& Tetlock, P. E. (1992). Allocating scarce resources: A contingency model of distributive justice. Journal of Experimental Social Psychology, 28, 491-522. https://doi.org/10.1016/0022-1031(92)90043-J

Slovic, P. (2010). The more who die, the less we care. In P. Slovic \& E. Michel-Kerjan (Eds.), The irrational economist: Making decisions in a dangerous world (pp. 30-40). New York: Public Affairs Press.

Smith, C., Ryder, P., Blais, M., \& Schneck, R. (2017). Evaluation of two different poverty simulations with professional phase pharmacy students. Currents in Pharmacy Teaching and Learning, 9, 903-910.

https://doi.org/10.1016/j.cptl.2017.05.018

Steck, L. W., Engler, J. N., Ligon, M., Druen, P. B., \& Cosgrove, E. (2011). Doing poverty: Learning outcomes among students participating in the Community Action Poverty Simulation program. Teaching Sociology, 39, 259-273. https://doi.org/10.1177/0092055X11407347

Stewart, J., Bleumers, L., Van Looy, J., Mariën, I., All, A., Schurmans, D.,. . Misuraca, G. (2013). The potential of digital games for empowerment and social inclusion of groups at risk of social and economic exclusion: Evidence and opportunity for policy [EUR scientific and technical report no. 25900 EN]. Seville, Spain: Institute for Prospective Technological Studies. Retrieved from: https://ec.europa.eu/jrc/en/publication/eur-scientific-and-technicalresearch-reports/potential-digital-games-empowerment-and-social-inclusion-groups-risk-social-and-economic

Strasser, S., Smith, M. O., Pendrick Denney, D., Jackson, M. C., \& Buckmaster, P. (2013). A poverty simulation to inform public health practice. American Journal of Health Education, 44, 259-264.

https://doi.org/10.1080/19325037.2013.811366

Tagler, M. J., \& Cozzarelli, C. (2013). Feelings toward the poor and beliefs about the causes of poverty: The role of affective-cognitive consistency in help-giving. The Journal of Psychology, 147, 517-539.

https://doi.org/10.1080/00223980.2012.718721

Todd, M., de Guzman, M. R. T. \& Zhang, X. (2011). Using poverty simulation for college students: A mixedmethods evaluation. Journal of Youth Development, 6(2), 72-77. https://doi.org/10.5195/JYD.2011.189

Todman, L. C., Brodyn, A., Berger, J., Willard, S., \& Taylor, J. S. (2013). Evaluation of the Social Exclusion Simulation: A training tool for professional psychology. Professional Psychology: Research and Practice, 44, 324 330. https://doi.org/10.1037/a0034643

Vandsburger, E., Duncan-Daston, R., Akerson, E., \& Dillon, T. (2010). The effects of poverty simulation, an experiential learning modality, on students' understanding of life in poverty. Journal of Teaching in Social Work, 30 , 300-316. https://doi.org/10.1080/08841233.2010.497129

Verhoeven, J. C., Heerwegh, D., \& De Wit, K. (2010). Information and communication technologies in the life of university freshmen: An analysis of change. Computers \& Education, 55, 53-66.

https://doi.org/10.1016/j.compedu.2009.12.002 
Vlachopoulos, D., \& Makri, A. (2017). The effect of games and simulations on higher education: A systematic literature review. International Journal of Educational Technology in Higher Education, 14, article 22.

https://doi.org/10.1186/s41239-017-0062-1

Wang, Y. W., Davidson, M. M., Yakushko, O. F., Savoy, H. B., Tan, J. A., \& Bleier, J. K. (2003). The scale of ethnocultural empathy: Development, validation, and reliability. Journal of Counseling Psychology, 50, 221-234. https://dx.doi.org/10.1037/0022-0167.50.2.221

Weiner, B., Osborne, D., \& Rudolph, U. (2011). An attributional analysis of reactions to poverty: The political ideology of the giver and the perceived morality of the receiver. Personality and Social Psychology Review, 15, 199213. https://doi.org/10.1177/1088868310387615

Willer, R., Wimer, C., \& Owens, L. A. (2015). What drives the gender gap in charitable giving? Lower empathy leads men to give less to poverty relief. Social Science Research, 52, 83-98.

https://doi.org/10.1016/j.ssresearch.2014.12.014

Yang, K., Woomer, G. R., Agbemenu, K., \& Williams, L. (2014). Relate better and judge less: Poverty simulation promoting culturally competent care in community health nursing. Nurse Education in Practice, 14, 680-685.

https://doi.org/10.1016/j.nepr.2014.09.001

Zosky, D., \& Thompson, J. (2012). Poverty simulation: An experiential learning tool emphasizing economic justice content. Journal of Baccalaureate Social Work, 17(1), 69-84. Retrieved from https://jbsw.org/doi/abs/10.5555/basw.17.1.1316126522m7h284

Zucker, G. S., \& Weiner, B. (1993). Conservatism and perceptions of poverty: An attributional analysis. Journal of Applied Social Psychology, 23, 925-943. https://doi.org/10.1111/j.1559-1816.1993.tb01014.x 


\title{
Correspondence to:
}

Pedro Hernández-Ramos

Department of Education

Santa Clara University

500 El Camino Real

Santa Clara, CA 95053

Email: phernandezramos(at)scu.edu

Editorial record: First submission received on October 8, 2018. Revisions received on March 29, 2019, and April 18, 2019. Accepted for publication on April 23, 2019.

Editor in charge: David Smahel

\begin{abstract}
About Authors
Pedro Hernández-Ramos (Ph.D., Stanford University, 1984) is an Associate Professor of Education at Santa Clara University. His research interests are centered in technology integration for K-12 teaching and learning, as well as the use of simulations and games_including virtual reality — for learning.

Christine M. Bachen (Ph.D., Stanford University, 1982) is an Associate Professor of Communication and the Director of Assessment at Santa Clara University. Her recent research focuses on civic learning from games, simulations, and virtual reality, and teaching practices that promote equitable learning among undergraduates.
\end{abstract}

Chad Raphael (Ph.D. Northwestern University, 1997) is a Professor of Communication at Santa Clara University. His research focuses on political communication, including public deliberation, environmental communication, and games and simulations for civic learning.

John Ifcher (Ph.D., University of California, Berkeley, 2004) is an Associate Professor of Economics at Santa Clara University. His recent research focuses on social welfare programs, subjective well-being, and decision making on behalf of others.

Michael Broghammer (B.A., Santa Clara University, 2018) is currently a graduate student at Pennsylvania State University. He studies political communication and public deliberation. 